\title{
When games are the only fashion in town: Covid-19, Animal Crossing, and the future of fashion
}

The fashion industry is articulated upon the personalities of bodies, the intimacy of the product's touch and feel, the community of trends and tribes. The effect of Covid-19 has been far-reaching and indiscriminate, not only for the maintenance of the practical and commercial infrastructure of fashion, but also for the very identity of fashion itself. In the first instance there was the very direct response of turning factories over to the production of protective equipment ${ }^{1}$ and the positioning of the face mask as a fashion item. ${ }^{2}$ The impact of the virus on production, including the closure of factories, has magnified already existing attention on outsourcing and the uncertain welfare of workers in poorer economies manufacturing the bulk of fast fashion. At the same time, slow fashion movements such as luxury rental may never recover. Fundamentally there has also been a transformative shift in fashion's identity. Fashion struggles with social distance and hoards trending products. Fashion has already been confronting its record on sustainability, but with the impact of the virus, the object of fashion's commercial model is moving even further away from that of the turnover of the individual product and closer to a discourse of reuse and duration. Ultimately, and perhaps inevitably, the fashion industry has had to reconcile a retail model of selling less product rather than more. Fashion is becoming less 'eventful' and the display of fashion's twenty-first-century boulevardier is increasingly a mediated and virtual presence, rather than a vibrant one. In this respect, the consumer's belief in the provenance of the fashion product (and the authenticity and assurance of labelling) becomes the object at stake and in transaction, rather than the product itself. The social life of fashion is thus becoming more difficult to recognize but, in many ways, also easier to find.

Covid-19 has presented specific challenges to the fashion industry, some well beyond the immediate retail relationship. Not only individual brands, but also to a large extent the industry itself, have been forced to re-position and secure identity and resilience. One particularly extraordinary phenomenon has been the translation of fashion into the fan communities of Animal Crossing: New Horizons, ${ }^{3}$ the latest release of Nintendo's social simulation video game series, Animal Crossing. I say extraordinary, but in many ways the fashioning of Animal Crossing and the gaming of fashion were a long time coming.

1. L Harper, 'UK Fashion Designers Join Hands to Make Scrubs for Key Workers', The Guardian, 17 April $2020<$ https://www.theguardian.com/fashion/2020/apr/17/uk-fashiondesigners-join-hands-to-make-scrubs-for-key-workers>.

2. For example, the British Fashion Council (BFC) and the Council of Fashion Designers of America (CDFA) launched a partnership for the production of designer face masks in July 2020. See N Campbell, 'CFDA and BFC Launch Great Global Designer Face Coverings', CFDA.com, 12 July $2020<$ https://cfda.com/news/cfda-bfc-launch-great-global-designer-face-coverings $>$.

3. Worldwide release, 20 March 2020. 
The pandemic has transformed not only fashion retail relationships but also predominant gaming cultures. ${ }^{4}$ Early in the pandemic, Animal Crossing outsold traditionally dominant players, such as Call of Duty, in what could be explained as a kind of socialization of the gaming stratosphere with a new diversity of 'unlikely' gamers. ${ }^{5}$ With its tagline of 'Your island, your life!' Animal Crossing promised players the tonic of a kind of control and social life that might be otherwise missing in the uncertainty of pandemic existence. As such, Animal Crossing has become a new kind of social bazaar, where participation in the game has developed into a kind of twenty-first-century virtual promenade, showcasing fashion, taste, and mobility, as it were, in a paradoxically secluded consumer society. Keza MacDonald, video games editor for The Guardian, says, 'it's a game about self-expression'?

The premise of Animal Crossing: New Horizons is to start a new life on an island, where your character will perform daily activities in real time, including collecting various items, basic agricultural tasks, shopping, trading, and socializing, as well as participating in in-game events. The game is open-ended and without specific objectives, apart from maintaining the general activities associated with developing your island. The economy of Animal Crossing is particularly interesting. As well as trading basic items for Bells, the local currency, players have the opportunity to invest in the Stalk Market - that is, in Turnips, sold weekly by the character, Daisy Mae. Just like the stock market, the Stalk Market is a way to yield high returns of Bells in a short period of time. However, also just like the actual stock market, the Stalk Market is both potentially profitable as well as very risky. Not only does the price of Turnips vary twice daily, but also the Turnips must be sold before the next week's marketplace as otherwise, just like real turnips, they will spoil and be worth nothing at all. ${ }^{8}$ Alongside the support from various online communities, ${ }^{9}$ the Stalk

4. S Liao, 'Why the Video Game Boom Is Here to Stay', CNN, 13 December 2020, <https:// edition.cnn.com/2020/12/13/tech/gaming-recession-proof/index.html>. See further Deloitte, 'Engaging Millennial and Gen Z Employees in the Post-Pandemic Future', Forbes, 16 September 2020, <https://www.forbes.com/sites/deloitte/2020/09/16/engaging-millennial-andgen-z-employees-in-the-post-pandemic-future/>.

5. M Sweney, 'Family-Friendly Animal Crossing Takes Video Game Top Spot Amid Lockdown', The Guardian, 23 April $2020<$ https://www.theguardian.com/games/2020/apr/23/ family-friendly-animal-crossing-takes-video-game-top-spot-amid-lockdown.> Sweney notes the game's 'wider multigenerational family fanbase than most bestselling titles', with 'Animal Crossing ... now the biggest single game launched on Nintendo Switch ... [and] proving to be an escapist antidote to the coronavirus pandemic'.

6. See the YouTube promotional video <https://youtu.be/5LAKjL3p6Gw>. One of the key characters throughout the whole Animal Crossing series is Tom Nook (also the game's real estate broker). With the release of New Horizons, Nook promised, 'With our Deserted Island Getaway Package, a carefree new life awaits you on a peaceful paradise of your own making, yes, yes!' See further the launch announcement: <https://www.nintendo.co.uk/Games/NintendoSwitch/Animal-Crossing-New-Horizons-1438623.html $>$.

7. EV Bramley, "It's a Way to Live Out Fantasies": How Animal Crossing Became Fashion's New Catwalk', The Guardian, 21 May $2020<\mathrm{https}: / / w w w . t h e g u a r d i a n . c o m / f a s h i o n / 2020 / m a y / 21 /$ its-a-way-to-live-out-fantasies-how-animal-crossing-became-fashions-new-catwalk> .

8. See further the guide in R Frushtick, 'Animal Crossing: New Horizons Guide to Selling Turnips', Polygon, 20 March $2020<$ https://www.polygon.com/animal-crossing-new-horizonsswitch-acnh-guide/2020/3/20/21181835/selling-turnips-stalk-market>.

9. For example, see the Facebook groups, Animal Crossing New Horizons Stalk Market $<$ https://www.facebook.com/groups/1386724848182585> and ACNH Inside Stalk Market $<$ https://www.facebook.com/groups/217915402636206>. 
Market spawned the Discord server, Daisy Mae's Exchange ${ }^{10}$ and an almost metagame system of Turnip price prediction calculators. ${ }^{11}$ In fact, the Stalk Market is so competitive that some islanders have even hired Turnip bouncers. ${ }^{12}$ Notably, however, much of the safety in the Stalk Market is protected through a system of manners and rules of etiquette, rather than conventions of property. And this kind of normative approach to 'regulating' the interactive environment provides notable insight into the kind of 'interactivity' seen in other cultural forms, including fashion, and the interaction with dominant configurations within intellectual property environments. Rather than the traditional barriers and digital fences of conventional property, that have no need for manners, the game depends upon a much more sociable approach to property and the mobile territories of the digital. When it comes to intellectual property in fashion and the interaction with fan communities and dynamic and 'interactive' selfidentity, the game thus becomes particularly compelling as a critical approach to the nature of property, including fashion.

This relationship between gaming and fashion is also not brand new, as it were. Under the creative direction of Jeremy Scott, Moschino has engaged prolifically with iconic brand images, including the famous example of the Fall 2014 so-called McDonald's collection. ${ }^{13}$ In 2019 Scott took the brand into virtual collections through the production of an in-game collection for The Sims 4 as well as a collaboration that translated into a ready-to-wear line in a mutually constitutive collaboration between the two worlds. For the in-game collection Scott explains, 'We took lots of our favorite pieces from the past few collections and made them for the virtual world of Sims 4'; while in the ready-to-wear collection the brand was 'reinterpreted into a pixel format', thus 'giving the illusion that your clothes are actually part of a computer simulation'. ${ }^{14}$

What is interesting about the Moschino and other collaborations is the way in which fashion is translated into a discourse of brand imagery, as distinct from conventional narratives of design. While one fashion writer describes Scott as 'fashion's most evolved connoisseur of junk culture', ${ }^{15}$ another sees this engagement with popular culture as actually remaking Moschino 'for the Instagram era'. ${ }^{16}$ In this way, luxury becomes unselfconsciously admitting of consumer culture. Notably, in the expansion of Animal Crossing's fashion prowess, Instagram has proven to be an

10. Daisy Mae's Exchange has since been expanded to include other games and has been renamed Community Crossroads <https://disboard.org/server/472924901095899146>.

11. For example, see Turnip Prophet $<$ https://turnipprophet.io $>$. See further the discussion in R Spear, 'Here's How Animal Crossing: New Horizons Simulates the Real-World Economy', iMore, 18 May $2020<\mathrm{https}$ ://www.imore.com/animal-crossing-new-horizons-turnip-exchangegroups-real-world-economy $>$.

12. P Hernandez, 'Animal Crossing Fans are Hiring Turnip Bouncers Now', Polygon, 10 April $2020<$ https://www.polygon.com/2020/4/10/21216737/animal-crossing-turnips-stalk-marketnew-horizons-acnh-bouncers-security>.

13. T Blanks, 'Moschino's Fall 2014 Ready-To-Wear', Vogue, 20 February $2014<$ https:// www.vogue.com/fashion-shows/fall-2014-ready-to-wear/moschino>.

14. Jeremy Scott quoted in M Rivas, 'Jeremy Scott Talks Designing Moschino Looks for The Sims', Refinery 29, 13 August 2019 <https://www.refinery29.com/en-us/2019/08/ 240397/jeremy-scott-moschino-the-sims>.

15. Blanks (n 13).

16. L Widdicombe, 'Barbie Boy: How Jeremy Scott Remade Moschino for the Instagram Era', New Yorker, 14 March 2016 <https://www.newyorker.com/magazine/2016/03/21/jeremy-scottsnew-moschino>. 
instrumental collaborator, particularly for official brand collaborations. ${ }^{17}$ Instagram accounts such as Crossing the Runway (which describes itself as 'The Original Animal Crossing Account'), ${ }^{18}$ Nook Street Market, ${ }^{19}$ and Animal Crossing Fashion Archive, ${ }^{20}$ have established fashion as a key experience in the Animal Crossing community. In many ways, Instagram is fundamental to the Animal Crossing fashion economy in order to capture attention for new designs, the most important generation of value in a Bells economy: 'The Animal Crossing fashion community can be intense. There's a lot of competition - not personal, or with each other, it's just getting eyes on your stuff. There's a lot of signal to noise. ${ }^{21}$ In other words, the competition is with attention, so to speak, rather than for it. There is an abundance of material, with no artificial rivalry or scarcity of fashion at the basis of this economy. Far from a traditional approach to competition, there is no limit to the fashion or the market. The only limit is attention.

The fashion credentials of Animal Crossing are extensive. In May 2020, Reference Festival, a 24-hour fashion festival launched in 2019, produced a virtual fashion show in collaboration with the Animal Crossing Fashion Archive and Marc Goehring, fashion director of 032C Magazine. ${ }^{22}$ The show consisted of Animal Crossing avatars dressed in current collections by Prada, Loewe, and $\mathrm{GmbH}$, reimagined for the virtual environment. ${ }^{23}$ The game itself includes a tailor shop, run by the Able Sisters - Mabel, Sable, and Label. ${ }^{24}$ But fans themselves have also developed collections ${ }^{25}$ as well as fashion inspired by a range of luxury brands ${ }^{26}$ and even character costumes for digital cosplay, ${ }^{27}$ raising some interesting questions regarding intellectual property. Of particular interest in this context is the use of trade marks, including examples of logomania and character merchandising within the game. The economy of Bells is thriving within Animal Crossing, but is this use of trade marks constituting use in the course of trade? And if so, is there some critical insight here for how the understanding of 'trade' must develop in order to account for brand development in social media?

17. While Instagram has been a dominant forum for collections, and certainly the one favoured by brands in official collections, fan communities have emerged elsewhere, such as in Reddit. See further the Animal Crossing fashion-focused subreddit at <https://www.reddit.com/r/ AnimalCrossing/comments/ipg4ch/fall_outfit_ideas_swipe_left_for_autumn_fashion/> and $<$ https://www.reddit.com/r/AnimalCrossing/comments/innq82/a_little_fall_fashion_guide_for_ island/>.

18. <https://www.instagram.com/crossingtherunway/?hl=en>.

19. <https://www.instagram.com/nookstreetmarket/?hl=en>.

20. <https://www.instagram.com/animalcrossingfashionarchive/?hl=en>.

21. Riley (Animal Crossing designer) quoted in C Marshall, 'Animal Crossing Keeps Growing a Vibrant Fashion Community', Polygon, 11 September $2020<\mathrm{https}$ ://www.polygon.com/2020/ 9/11/21432219/animal-crossing-fashion-influencers-designers-dress-sharing-community>.

22. <https://032c.com>.

23. S Yotka, 'The World's First Animal Crossing Fashion Show Is Here', Vogue, 25 May $2020<$ https://www.vogue.co.uk/news/article/animal-crossing-fashion-show>.

24. See the explanation of Label's fashion challenge at Eurogamer: <https://www.eurogamer. net/articles/animal-crossing-label-fashion-challenge-rewards-new-horizons-7018>.

25. For example, see the discussion of the development of an artistic community of fashion designers in Marshall (n 21).

26. See the Creative Bloq feature on fashion designs at $<\mathrm{https}: / / \mathrm{www}$.creativebloq.com/features/ animal-crossing-fashion/3>.

27. See the Creative Bloq feature on cosplay at $<$ https://www.creativebloq.com/features/animalcrossing-fashion>. 
Arguably, the economy of Animal Crossing is more than just 'Bells' (and whistles). What is especially interesting about the game is the way in which it compels a more innovative approach to the question of 'trade' in a hybrid physical/digital retail environment.

While 'bootleg' collections have proliferated within the game, ${ }^{28}$ other brands have created official Animal Crossing collections. Both Valentino ${ }^{29}$ and Marc Jacobs ${ }^{30}$ were early in populating the game with official collections or re-worked designs which users could download, thereby directing engagement with the brands' official Instagram accounts. ${ }^{31}$ And Hypebae, the fashion editorial division of Hypebeast, hosted their own live fashion show within the game in May, in which players were invited to model their creations on an island customized with its own outdoor runway. ${ }^{32}$ Nook Street Market opened the show in reimagined Jean Paul Gaultier Fall/ Winter 1995. ${ }^{33}$ This past Autumn, Carolina Sarria presented her latest fashion show $^{34}$ within the game with an in-game collection valued in an outside-game economy, each item bearing the modest price of US $\$ 5$ for the opportunity to download to wear within the game. ${ }^{35}$ The Instagram handle for each player model was also included in the show, emphasizing the importance of growing the individual player 'brand' within the economy of the game and complicating further the questions of play and trade.

Whether accepted as fan-based tributes outside the course of trade, or produced by the brand itself as digital products for in-game play, in this way the economy of fashion is thus reimagined outside the artefact through a familiar production with fans, realizing value outside the physical object itself. And at the same time, quite importantly, this raises questions about the commercial context for trade marks more broadly speaking. Within the Animal Crossing universe, arguably the use of fashion trade marks is transformed, yet still within a wholly commercial relationship.

This gamification of fashion imports the logic of the game into fashion itself. Late last year, Balenciaga launched its Autumn/Winter 2021 collection in an original video game. ${ }^{36}$ The strategy exploits the immersive, narrative aspects of the video game at a time when traditional forms of fashion interaction are challenging or impossible. This use of socalled 'advergames' has in fact been around in fashion for some time. Advergames are a form advertising in which a game is developed for the purpose of advertising

28. Bramley (n 7).

29. For example, see <https://www.instagram.com/p/B_r6dOLpHca/?hl=en>.

30. For example, see $<\mathrm{https}: / / \mathrm{www}$. instagram.com/p/B_szSLRDdW3/?hl=en>.

31. See further the discussion in J Fingas, 'Top Fashion Houses are Showing their Latest Styles in "Animal Crossing", engadget, 10 May $2020<$ https://www.engadget.com/animalcrossing-fashion-houses-231541432.html $>$.

32. A brief 'behind the scenes' of the show is available at $<$ https://www.youtube.com/watch? $\mathrm{v}=\mathrm{zsyj} 2 \mathrm{v} 3$ PvrU\&ab_channel=HYPEBAE $>$.

33. See the full story at $<$ https://hypebae.com/2020/5/hypebae-animal-crossing-new-horizonsfashion-show-runway-online-virtual-event-nintendo-switch-stream $>$.

34. See the show at $<$ https://www.youtube.com/watch?v=ayHvG23Tk9w\&feature =emb $\log 0>$. See further S Yotka, 'Carolina Sarria Brings the Community of Fashion Week to an Animal Crossing Show', Vogue, 3 September $2020<$ https://www.vogue.co.uk/fashion/article/ carolina-sarria-animal-crossing-fashion>.

35. <http://www.carolinasarria.com/animal-crossing-collection>.

36. BBC Editorial, 'Balenciaga to Unveil New Collection in Video Game', BBC News, 27 November $2020<$ https://www.bbc.co.uk/news/technology-55103957>. 
a particular product. ${ }^{37}$ In fact, the first known example of what would become known as an advergame was in fashion, when in 1978 Polo developed, but ultimately cancelled before release, a game for Atari 2600 to launch a cologne. ${ }^{38}$ In 2012, Jean Paul Gaultier launched the advergame, The Naughty Christmas, ${ }^{39}$ an advent calendar where players would access mini-games by opening each window. The windows were pockets inside the coat designed by Jean Paul Gaultier and worn by his avatar within the game. And in 2015, the sportswear brand, Björn Borg, launched a new collection through an advergame entitled First Person Lover and supported by a complementary campaign on social media. ${ }^{40}$ The game was based on the first-person shooter genre in which players shoot off clothing with 'love bombs' and replace them with the new collection. The game was launched at Fashion Week with a physical show that reflected the game, with models wearing masks from the playable characters. Several years before Jeremy Scott pixelated Moschino, Björn Borg love bombed fashion with teddy bear smoke grenades. ${ }^{41}$

With the current attention on sustainability and post-Covid restraint, the relationship between games and fashion has entered the mainstream. The appropriation by 'unlikely' gamers is translating fashion consumer culture into an economy of cultural as distinct from financial capital: 'It's a way to live out fashion fantasies without having to pay the steep price. ${ }^{42}$ In this way, it is possible that Animal Crossing can teach fashion how to sell more by making less. And it is assisted by an environment that already has an appetite for virtual fashion. In 2019, a digital dress, existing solely virtually, was sold for $\$ 9500$ at auction on blockchain. ${ }^{43} \mathrm{~A}$ few months later, Scandinavian retailer, Carlings, offered an entirely digital collection. ${ }^{44}$ Their rationale? 'Online influencers wear "real" clothes. But why? Their followers only see the digital image of the clothes. Swipe, like and move on to the next image. Three seconds of exposure and

37. One of the first examples of the use of the term 'advergame' is in Wired's 'Jargon Watch', where it is defined as 'A downloadable or Web-based game created solely to enable product placements' < https://www.wired.com/2001/10/jargon-watch-75/>. See further the extensive treatment of advergames (including their use in the Jean Paul Gaultier and Björn Borg examples discussed below) in T de la Hera, Digital Gaming and the Advertising Landscape (Amsterdam University Press, Amsterdam 2019) Chapter 6.

38. <http://www.atariprotos.com/2600/software/polo/polo.htm>.

39. Produced by Isobar, Fighting Fish and CRCR. See <https://thefwa.com/cases/jp-gaultierthe-naughty-christmas $>$. See further the launch video <https://www.youtube.com/watch? $\mathrm{v}=\mathrm{AiY}-$ AnDloyA $>$.

40. Produced by Garbergs (Stockholm) <http://webcollection.se/bjornborg/fpl/integrated. html>. See further the discussion in A Robertson, 'First Person Lover is a Shooter that Replaces Bullets with Feelings', The Verge, 5 February $2015<$ https://www.theverge.com/ 2015/2/5/7987505/first-person-lover-shooter-pastiche-bjorn-borg $>$.

41. See further the discussion of persuasion through the use of advergames in fashion in de la Hera (n 37).

42. Michele Yue of Nook Street Market quoted in Bramley (n 7).

43. <https://www.instagram.com/p/BxVzibUopFM/?hl=en>. See further the discussion in J Fingas, 'A Digital “Dress” Sold for \$9500', engadget, 27 May $2019<$ https://www.engadget. com/2019-05-27-fabricant-blockchain-digital-dress.html> and C Godwin, 'The £7,500 Dress that Does Not Exist', BBC News, 15 November $2019<\mathrm{https}$ //www.bbc.co.uk/news/business49794403>.

44. <https://www.jantrendman.com/en/trends/carlings-digital-collection>. See further the report in N May, 'These Clothes Aren't Real, They're All Digital: Is This the Future of Fashion?', Evening Standard, 14 November 2019 <https://www.standard.co.uk/insider/fashion/digital-fashionthe-fabricant-carlings-a4286496.html $>$. 
the look is old news. The solution: digital clothes. One algorithm fits all. ${ }^{45}$ Abi Buller of The Future Laboratory says, 'We could see brands launching a digital twin of physical products. We know that consumers shop to buy new outfits that they can share on social media, but they don't necessarily have to buy a physical garment to do that. They could buy digital versions of clothing products that could be added into photos and get the same experience. ${ }^{46}$ Animal Crossing, in ways very similar to Instagram's \#OOTD (outfit of the day), plays, as it were, into this very social environment of attention. And digital models have emerged not only for the purposes of advertising ${ }^{47}$ but also as influencers and brands in their own capacity. ${ }^{48}$ There are now digital modelling agencies, ${ }^{49}$ raising questions over the employment opportunities for living models as well as the potential manipulation of imagery and brand legacy. ${ }^{50}$ But in the gamification of fashion, the emergence of digital stars is all but inevitable. And during the pandemic, when traditional photo shoots became impossible, 'images that are made through a combination of model and machine are proving to be remarkably prescient' ${ }^{51}$ In a 'Bells' economy, as it were, the digital is becoming more and more as fashion gets on with the business of making less.

The new boulevardier is digital. And the new capital is sartorial. In fashion, the games are afoot.

Johanna Gibson January 2021

45. <https://www.jantrendman.com/en/trends/carlings-digital-collection>.

46. Quoted in E Sutherland, 'The New Directions for Fashion Retail', Drapers, 10 December $2020<\mathrm{https}$ ///www.drapersonline.com/insight/analysis/the-new-directions-for-fashion-retail $>$. Buller goes on to note the influence of Animal Crossing: 'Virtual fashion is already a growing trend - many brands have launched digital versions of products for avatars in Animal Crossing.' 47. For example, see the Balmain campaign discussed in R Hosie, (2018) 'Balmain Reveals Line-Up of Virtual Models for Latest Campaign', The Independent, 3 September 2018 $<$ https://www.independent.co.uk/life-style/fashion/balmain-virtual-models-digital-campaignfashion-shudu-a8520871.html>.

48. G Graham, '2018 was the Year AI Influencers and Digital Models Took Over Fashion', Dazed, 10 December 2018 <https://www.dazeddigital.com/fashion/article/42484/1/cgi-modelsai-influencers-lil-miquela-digital-models-trend-shudu-noonoouri> .

49. See The Diigitals <https://www.thediigitals.com/models $>$. See further S Semic, 'Meet The Man Behind The World's First Digital Supermodel', Elle, 15 July $2019<$ https://www.elle.com/ uk/fashion/a28394357/man-behind-worlds-first-digital-supermodel/>.

50. For a discussion of CGI in acting and the use of CGI actors, please see J Gibson, (2019) 'Where Have You Been? CGI Film Stars and Reanimation Horrors' (2019) 10(1) Queen Mary Journal of Intellectual Property 1-6 <https://www.elgaronline.com/view/journals/qmjip/10-1/ qmjip.2020.01.00.xml>.

51. M McDowell, 'During the Pandemic, Models get a Digital Makeover', Vogue, 21 April $2020<\mathrm{https}: / / \mathrm{www}$.voguebusiness.com/technology/during-the-pandemic-models-get-a-digitalmakeover-covid-19>. 